\title{
Spinal Somatosensory Evoked Potentials in Patients with Tethered Cord Syndrome
}

\author{
Alberto Polo, Giampietro Zanette, Paolo Manganotti, Laura Bertolasi, \\ Domenico De Grandis and Nicolo’ Rizzuto
}

\begin{abstract}
We studied the electrophysiological changes occurring in six patients with tethered cord syndrome. Evidence of spinal malformations was provided by magnetic resonance imaging. The functional assessment of the spinal cord was performed by analysing both spinal and cortical somatosensory evoked potentials. The evoked electrospinogram was recorded from the thoracic and lumbosacral spinous processes. The N22 lumbosacral potential was selectively affected, being rostrocaudally displaced and reduced in amplitude or even absent in patients with neurological signs indicating a segmental lower cord lesion. Inter-peak somatosensory evoked potentials latency was normal in all cases, suggesting that ascending axonal potentials in the dorsal column fibres may be synchronized. Segmental potentials of the lumbosacral response, originating from the post-synaptic activity of dorsal horn interneurons, are selectively affected in this syndrome resulting from the rostrocaudal displacement of the spinal cord due to tethering. Our findings in the clinical field are consistent with previous experimental evidence indicating a different sensitivity of the gray vs. white matter to progressive stretching.
\end{abstract}

\begin{abstract}
Résumé: Potentiels évoqués somesthésiques spinaux chez les patients atteints du syndrome du filum terminale. Nous avons étudié les changements électrophysiologiques présents chez six patients atteints du syndrome du filum terminale. Les malformations médullaires étaient détectées par résonance magnétique nucléaire. L'évaluation fonctionnelle de la moelle épinière était effectuée par l'analyse des potentiels évoqués somesthésiques spinaux et corticaux (PES). L'électrospinogramme évoqué était enregistré au niveau des apophyses épineuses thoraciques et lombosacrées. Le potentiel lombosacré N22 était sélectivement atteint: il était déplacé en position rostrocaudale et son amplitude était réduite et il était absent chez les patients qui avaient des signes neurologiques indiquant une lésion segmentaire basse de la moelle épinière. La latence interpics des PES était normale chez tous les cas suggérant que les potentiels axonaux ascendants des fibres du faisceau postérieur sont synchronisés. Les potentiels segmentaires de la réponse lombosacrée originant de l'activité post-synaptique des neurones intercalaires de la corne postérieure de la moelle sont atteints sélectivement dans ce syndrome dû au déplacement rostrocaudal de la moelle épinière par fixation caudale. Nos observations cliniques sont en accord avec les données expérimentales indiquant une sensibilité différente de la substance grise et de la substance blanche à l'étirement progressif.
\end{abstract}

Can. J. Neurol. Sci. 1994; 21: 325-330

The "tethered cord syndrome" (TCS) is a progressive neurological dysfunction presumably due to longitudinal traction of the lower spinal cord. The tethering has been attributed to a variety of pathological entities, ${ }^{1-6}$ and the morphological changes are now well established by neuroimaging. ${ }^{7.8}$ Although the clinical signs and symptoms can be classified as a mainly orthopaedic syndrome or as a mainly neurological syndrome, ${ }^{5,9}$ differences in the mode of onset, clinical manifestations and outcome exist between paediatric and adult patients. ${ }^{10-12}$ In the opinion of most authors, it is the degree of traction on the conus that determines the age when symptoms set in. ${ }^{9.11}$ It is therefore possible that discrete tethering without severe stretching may remain subclinical in childhood. Precipitating factors, mainly traumatic injuries, produce damage to the lumbosacral cord by upsetting the balance between abnormal tension and optimal cellular function. The adult form of TCS presents a picture of low back pain, progressive wasting and muscular atrophy of the legs, which may be long-standing and stable over a lengthy period or progressive, associated or not with upper motor neuron involvement. A functional investigation of the spinal cord may be provided by somatosensory and motor evoked potentials which assess the conduction along the central pathways. Moreover, it is now widely accepted that lumbosacral somatosensory evoked potentials (SEPs) may also provide information on the post-synaptic activity of the dorsal horn interneurons in response to non-noxious inputs. ${ }^{13-15}$

Separate components with a characteristic field distribution have been observed in the human evoked electrospinogram (EESG) following stimulation of mixed nerves in the leg. ${ }^{16,17}$ In monopolar surface recordings, posterior tibial nerve stimulation

From the Dipartimento di Scienze Neurologiche E Della Visione. Sezione Neurologia, Universita' Degli Studi di Verona (A.P., G.Z., P.M., L.B.) and the Divisione di Neurologia, Arcispedale S. Anna, Ferrara (D. de G., N.R.).

RECEIVED FEBRUARY 10, 1994. ACCEPTED IN FINAL FORM JUNE 16, 1994.

Reprint requests to: Alberto Polo M.D. Dipanimento di Scienze Neurologiche E Della Visione, Sezione Neurologia, Universita' Degli Studi di Verona, Policlinico Borgo Roma, via Delle Menegone, 37134 - Verona, Italy. 
evoked a first positive far-field potential (P15) generated by the afferent volley in the proximal portion of the lumbosacral plexus. ${ }^{18,19}$ Following this potential, two different negative peaks arise from the thoracolumbar regions. ${ }^{20.21}$ The first travelling wave (N18) probably reflects the afferent volley along the dorsal roots of the cauda equina. The second stationary peak (N22) represents the post-synaptic neural activity in laminae IV and $\mathrm{V}$ of the dorsal horn during activation of large-diameter afferent fibres. ${ }^{22}$

The possibility of finding a clear dissociation between normal cauda equina and scalp responses and an abnormal N22 spinal potential was first suggested by investigators who found a spinal N22 not serial with the ascending somatosensory volley. ${ }^{17}$

Evoked potential studies have been conducted in patients with early-onset TCS, which is by far the most common and severe form. ${ }^{23}$ A literature survey revealed approximately 50 anedoctal accounts of TCS with symptom onset in adulthood, but most studies lack precise clinico-pathological correlations. ${ }^{10}$

In this work, we evaluated somatosensory evoked potentials (SEPs) in 6 patients with adult TCS confirmed by radiological investigations. Our aim was to study the effect of spinal cord displacement due to stretching not only on the conduction along the ascending and descending cord pathways, but also on the waveform and field distribution of the EESG. The electrophysiological findings were correlated with the clinical picture.

\section{METHODS}

\section{Patients}

In the present study, the patients were subgrouped into two categories as proposed by Pang et al.: ${ }^{10} \mathrm{~A}$ ) those who were normal as children but developed symptoms in adulthood, and B) those with static neurological deformities diagnosed in childhood but who remained well until the onset of new, progressive neurological deficits in adulthood.

A) Two females, patients 1 and 2 in Table 1, were referred to our institute complaining of chronic low back pain as the main symptom, mostly aggravated by prolonged sitting and standing. One of them also complained of a progressive weakness of the legs during walking. In both cases clear-cut circumstances (fall on the buttocks, leg-stretching exercises) led to the onset of symptoms. Spinal MRI showed an enlarged lumbosacral sac with a low-lying conus stretched against the posterior wall of the canal.

B) Three females and one male (patients 3 to 6 in Table 1) showed a long-standing discrete deformity of the foot (pes cavus), segmental or diffuse hypotrophy of the leg muscles. All patients presented with a several-year history of intermittent or chronic low back pain. Surgical intervention, pregnancy and spinal trauma were indicated as clear-cut circumstances undoubtedly worsening the course of the disease.

MRI showed spinal malformations associated with a tethered cord (Figure 1). In all patients (groups A and B) vibratory sensation and joint position sense were intact.

The general physical examination yielded negative findings.

\section{METHOD}

Lower-limb SEPs were recorded following electrical stimulation consisting of square-wave pulses at a rate of $4 / \mathrm{sec}$ applied to the posterior tibial nerve at the ankle; stimulus intensity was adjusted so that each stimulus just produced a visible plantar flexion of the big toe. Spinal SEPs were obtained with a linear

\section{Table 1.}

\begin{tabular}{|c|c|c|c|c|c|c|}
\hline PT & AGE & HEIGHT & SEX & SYMPTOMS & SIGNS & MRI \\
\hline 1) & 42 & 162 & $\mathrm{~F}$ & $\begin{array}{l}\text { low back pain } \\
\text { neurogenic claudicatio }\end{array}$ & absent & $\begin{array}{l}\text { low lying conus } \\
\text { thickened filum }\end{array}$ \\
\hline 2) & 46 & 164 & $\mathbf{F}$ & low back pain & absent & $\begin{array}{l}\text { low lying conus } \\
\text { thickened filum }\end{array}$ \\
\hline \multirow[t]{2}{*}{ 3) } & 62 & 166 & $\mathrm{~F}$ & low back pain & pes cavus & $\begin{array}{l}\text { sacral meningocele } \\
\text { intradural lipoma }\end{array}$ \\
\hline & & & & $\begin{array}{l}\text { weakness of the feet } \\
\text { dorsiflexion }\end{array}$ & $\begin{array}{l}\text { hypotrophy of the } \\
\text { anterior leg }\end{array}$ & \\
\hline \multirow[t]{2}{*}{ 4) } & 54 & 160 & $\mathbf{M}$ & low back pain & $\begin{array}{l}\text { diffuse left leg } \\
\text { hypotrophy }\end{array}$ & $\begin{array}{l}\text { fatty tissue within the } \\
\text { lower part of filum } \\
\text { terminale }\end{array}$ \\
\hline & & & & $\begin{array}{l}\text { sphincter disturbances } \\
\text { left leg weakness }\end{array}$ & $\begin{array}{l}\text { pes cavus } \\
\text { hyporeflexia }\end{array}$ & \\
\hline \multirow[t]{2}{*}{ 5) } & 33 & 168 & $\mathrm{~F}$ & low back pain & $\begin{array}{l}\text { anterior leg } \\
\text { hypotrophy }\end{array}$ & $\begin{array}{l}\text { lipomatous } \\
\text { degeneration of filum } \\
\text { terminale }\end{array}$ \\
\hline & & & & $\begin{array}{l}\text { weakness of foot } \\
\text { dorsiflexion } \\
\text { sphincter disturbances } \\
\text { slight spastic gait }\end{array}$ & $\begin{array}{l}\text { pes cavus } \\
\text { brisk reflexes }\end{array}$ & \\
\hline \multirow[t]{2}{*}{ 6) } & 64 & 158 & $\mathrm{~F}$ & low back pain & $\begin{array}{l}\text { hypotrophy of } \\
\text { posterior legs }\end{array}$ & $\begin{array}{l}\text { Sacral meningocele } \\
\text { with lipoma adherent to } \\
\text { SI root }\end{array}$ \\
\hline & & & & $\begin{array}{l}\text { lightning sensations } \\
\text { on the left buttock } \\
\text { weakness of the legs } \\
\text { sphincter disturbances }\end{array}$ & $\begin{array}{l}\text { absent Achille's } \\
\text { tendon reflexes } \\
\text { foot deformity }\end{array}$ & \\
\hline
\end{tabular}




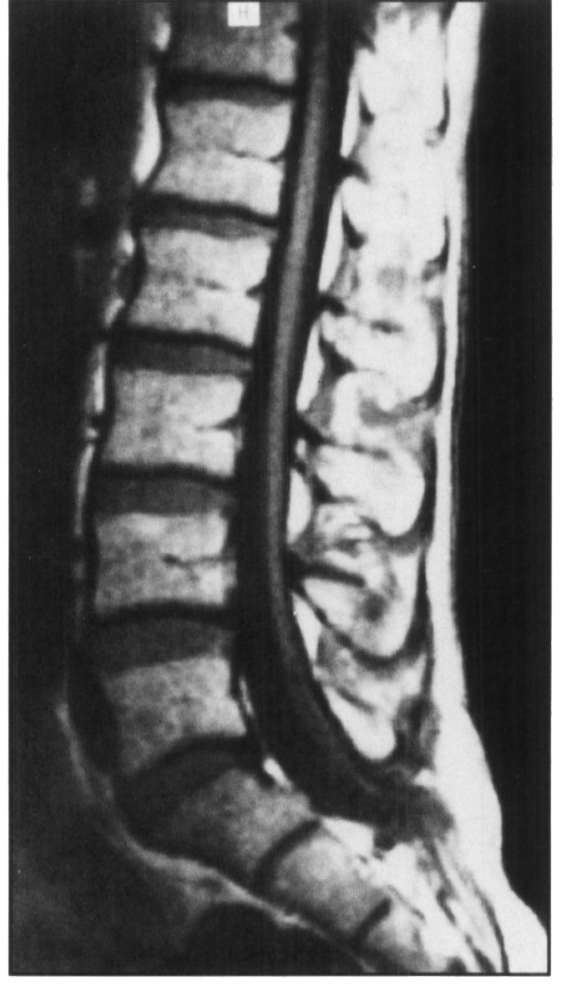

Figure 1: Tethered cord in a 54-year-old woman with low back pain and spinal claudicatio (patient 4). MRI shows enlargement of the sacral canal, a low-lying conus medullaris, a thickened terminal filament stretched against the posterior wall of the lumbo-sacral canal. Mid-sagittal section, spin-echo (SE) sequence TR: 500 TE: 15.

array of eight monopolar needle electrodes (12 $\mathrm{mm}$ in length) located over the S1, L4, L2, T12, T10, T8, T6 and T4 spinous processes (EESG) commonly referenced to the iliac crest ipsilateral to the site of stimulus). Scalp SEPs were recorded with a $\mathrm{Cz}-\mathrm{Fz}$ montage.

Simultaneous 4-channel recordings were obtained by setting band passes of $20-2000 \mathrm{~Hz}$ and $5-2000 \mathrm{~Hz}$ for spinal and scalp SEPs, respectively. The averaged potential was obtained from 500 artifact-free responses. All trials were repeated at least once to ensure stability and reliability of evoked potentials. We considered the following parameters for data analysis: latency of P15, latency and amplitude distribution of N22, latency of the scalp P37; the mean P15-N22 inter-peak time was measured to offset the influence of stature; the mean P15-P37 inter-peak time allowed assessment of conduction of the ascending volley from the proximal extra-spinal somatosensory pathways to the brain.

The amplitude ratio of $\mathrm{N} 22$ wave between $\mathrm{T} 10, \mathrm{~T} 12, \mathrm{~L} 2$ and L4 may provide further informations concerning the relationships between maximum amplitude location and amplitude distribution in the EESG (Table 2).

The responses (four consecutive traces were superimposed to assess the reliability) were recorded simultaneously on the right and left side using a filter band-pass of $20-2000 \mathrm{~Hz}$.

Normal values were obtained by studying a control group of 23 aged-matched healthy subjects (mean age 43 ); means and standard deviations (SD) were calculated from values of both sides.
Table 2. SEP latency and amplitude in 23 healthy subjects (mean age 43).

\begin{tabular}{lcc}
\hline Peak latency (ms) & Mean & SD \\
P15 & 14.8 & 1.22 \\
N18 & 18.1 & 1.30 \\
N22 & 21.6 & 1.32 \\
P37 & 36.2 & 1.48 \\
& & \\
Interpeak latency (ms) & 6.7 & \\
P15-N22 & 21.5 & 0.6 \\
P15-N37 & & 1.04 \\
& & \\
N22 amplitude distribution $(\mu$ V) & 0.42 & 0.13 \\
T8 & 0.93 & 0.31 \\
T10 & 0.98 & 0.51 \\
T12 & 0.56 & 0.12 \\
L2 & 0.21 & 0.10 \\
L4 & & \\
& & Minimum \\
N22 amplitude ratio & Mean & value \\
T10/L4 & 4.43 & 3.1 \\
T12/L4 & 4.67 & 3.8 \\
L2/L4 & 2.67 & 1.3
\end{tabular}

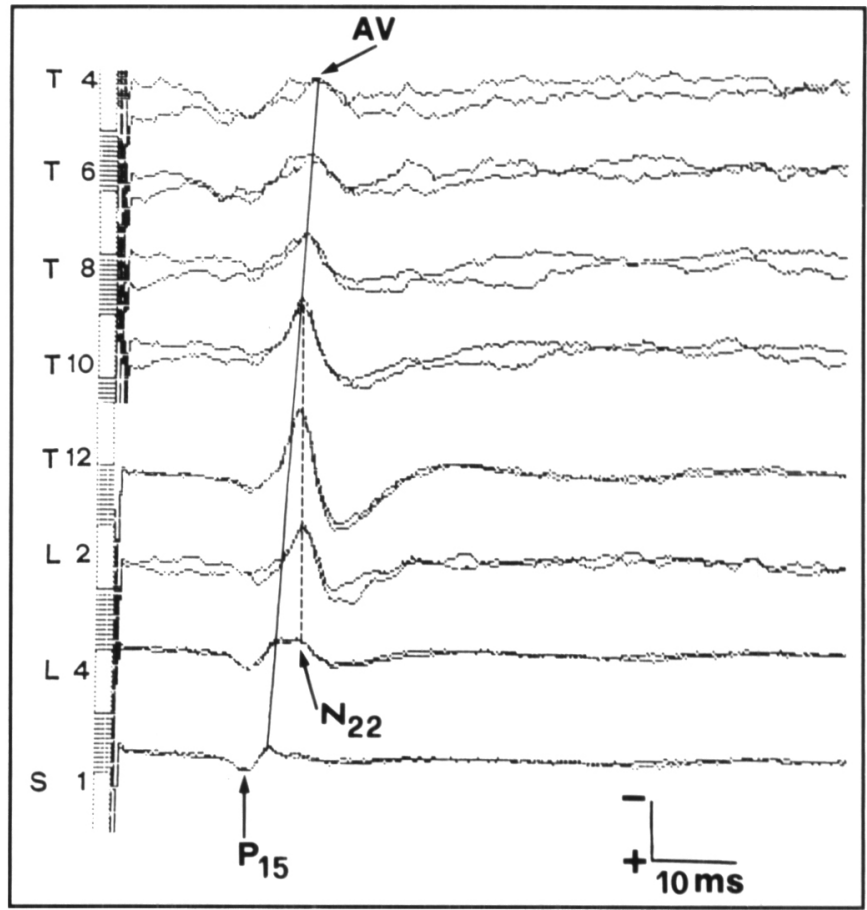

Figure 2: Evoked electrospinogram (EESG) in a normal subject. Recordings are obtained from the dorsal midline following stimulation of the posterior tibial nerve at the ankle. Electrode positions are the corresponding spinous process (on the left): the common reference is the iliac crest ipsilateral to the stimulus. The EESG peaks are labelled according to their positive $(P)$ or negative $(N)$ polarities at the "active" electrode and labelled with nominal latencies reflecting the mean latency for each peak in our control group. The stationary plexus potential is indicated as P15. The solid line connects the peaks of the travelling wave labelled the afferent volley (AV). Dashed line show the stationary peak labelled as N22 (post-synaptic potential). The highest amplitude of the spinal complex is observed at the lower thoracic sites. 


\section{RESULTS}

The typical waveform and distribution of the normal EESG are illustrated in Figure 2. The first positive "far-field" potential (P15) is followed by two negative peaks: the earlier peak is an ascending negative wave (AV, afferent volley or N18) gradually increasing in latency from the sacral to the upper thoracic regions; the second is a stationary wave (N22) with a maximum amplitude at the lower thoracic sites. Both these components are clearly distinguishable at lumbosacral sites, while at more rostral leads a prominent negativity merges into the potential labelled N22.

Table 2 shows the reference data for SEPs. Values exceeding the mean plus $2.5 \mathrm{SD}$ were regarded as abnormal.

In both patients ( 1 and 2 ) with pure tethered cord there was a caudal displacement of the potentials. The first positive far-field potential has a mean latency of $14.3 \mathrm{msec}$ (1.0 SD). The maximum amplitude of the spinal complex appears at the lower lumbar sites, where a simple negative peak may be observed; the mean latency was $19.8 \mathrm{msec}(0.9 \mathrm{SD})$ and mean amplitude measured $0.26 \mu \mathrm{V}(0.12 \mathrm{SD})$. N22 was not found at the recording level of T12 and T10. The patients showed a shorter P15-N22 inter-peak time $(<5.2 \mathrm{msec})$ than the normal P15-N22 value minus $2.5 \mathrm{SD}$. This change could be due to the anatomical discrepancies between the spine and spinal cord, i.e., the nerve roots take a horizontal course with a shortening of the intracanalar length. The later, slow positive wave is not consistent in consecutive recordings. The P37 early scalp potential had a mean latency of $36.2 \mathrm{msec}$ (1.1 SD) displaying normal amplitude and waveform. The EESG for patient 1 is shown in Figure 3.

Patients with tethered cord and associated malformations in the lumbosacral canal showed more marked abnormalities of segmental spinal SEPs, i.e., a loss of N22 potentials. The earlier stationary positive peak occurred with a mean latency of 14.5 msec (0.93 SD). A later negative peak, similar in latency and waveform to $\mathrm{N} 18$, is recorded at lower lumbar sites with a mean latency of $18.5 \mathrm{msec}(0.83 \mathrm{SD})$; a second negative peak, i.e., the $\mathrm{N} 22$ component, and the subsequent slow negativity are not detectable. At the T12 and T10 recording sites, the spinal components following the plexus potential presented minimal EESG amplitudes. The negative peak reflecting the afferent volley was clearly defined at more rostral sites, suggesting the integrity of dorsal column conduction. Figure 4 illustrates case 3 .

The P37 early scalp potential occurred with a mean latency of $37.4 \mathrm{msec}$ ( $1.25 \mathrm{SD}$ ); the waveforms of the cortical responses were normal.

\section{Discussion}

Few SEP investigations have been conducted in patients with TCS, and these are extensive only in the early-onset form. Absent, delayed or low-amplitude lumbar spinal potentials following posterior nerve stimulation have been observed. The absence of N14 (N22 lumbar spinal cord EP in the adult) at the L1 site was interpreted as a lesion affecting the posterior columns. N14 abnormalities alone were also considered to reflect the extent of spinal involvement, as shown by myelography, as regards the location and direction of the tethering structure. $^{23}$

An abnormal surface distribution of the lumbosacral EESG, and particularly of the stationary $\mathrm{N} 22$ wave, has been reported in young patients with myelographically confirmed tethered cord: SEP changes were only evaluated to confirm the conus displacement. ${ }^{24}$

SEPs have also been used to evaluate pre-operative findings in patients with adult-onset TCS due to fibrous diastematomyelia ${ }^{4}$ and to monitor spinal cord tethering during surgery. ${ }^{6.25}$

In our cases, we found a characteristic abnormality within segmental spinal SEPs: while the potentials generated by the proximal plexus volley and by the afferent dorsal roots were spared, the post-synaptic spinal potential was caudally displaced and drastically reduced in amplitude or even absent. This selective involvement of spinal potentials was associated with normal scalp SEPs.

In healthy subjects, the N22 peak was greatest between the $\mathrm{T} 10$ and $\mathrm{L} 2$ spinous processes, a region overlying the spinal

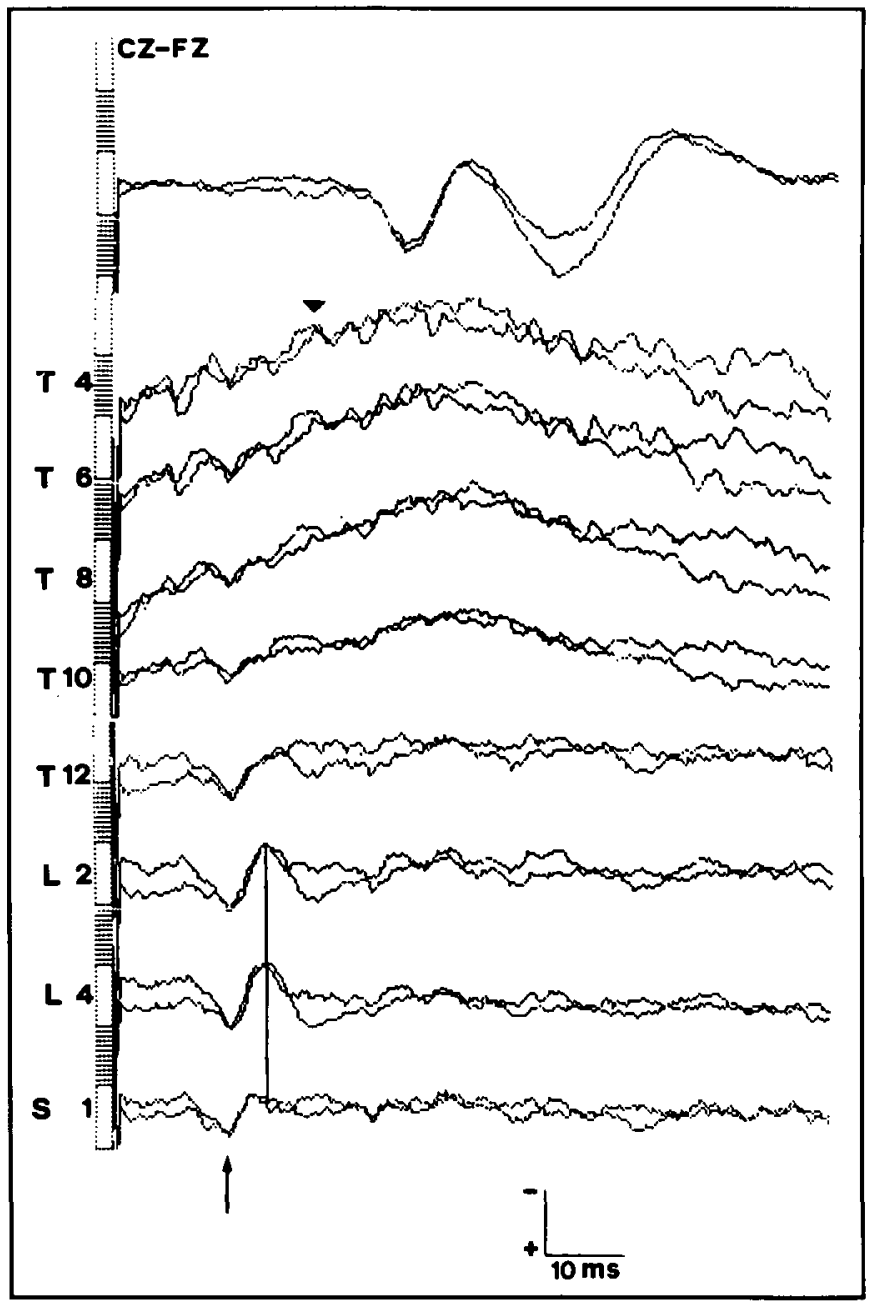

Figure 3: EESG and scalp SEPs in patient 1. The plexus stationary potential is normally represented (arrow at bottom). The spinal complex is reduced in size and caudally displaced as compared to the usual topography in normal subjects. The latency of the major negative peaks (a probable N22) from the L2 and L4 sites is exactly the same (vertical line); a shorter negative peak (afferent volley) is recorded from the SI site. The arrow in the upper EESG traces shows the afferent volley at rostral level. At the top, the latency $(36.2 \mathrm{msec})$ and amplitude of the scalp responses (CZ-FZ montage) are found to be within normal limits. Calibration: $0.65 \mu \mathrm{V} /$ div in EESG, $1.3 \mu \mathrm{V} /$ div scalp SEPs. 


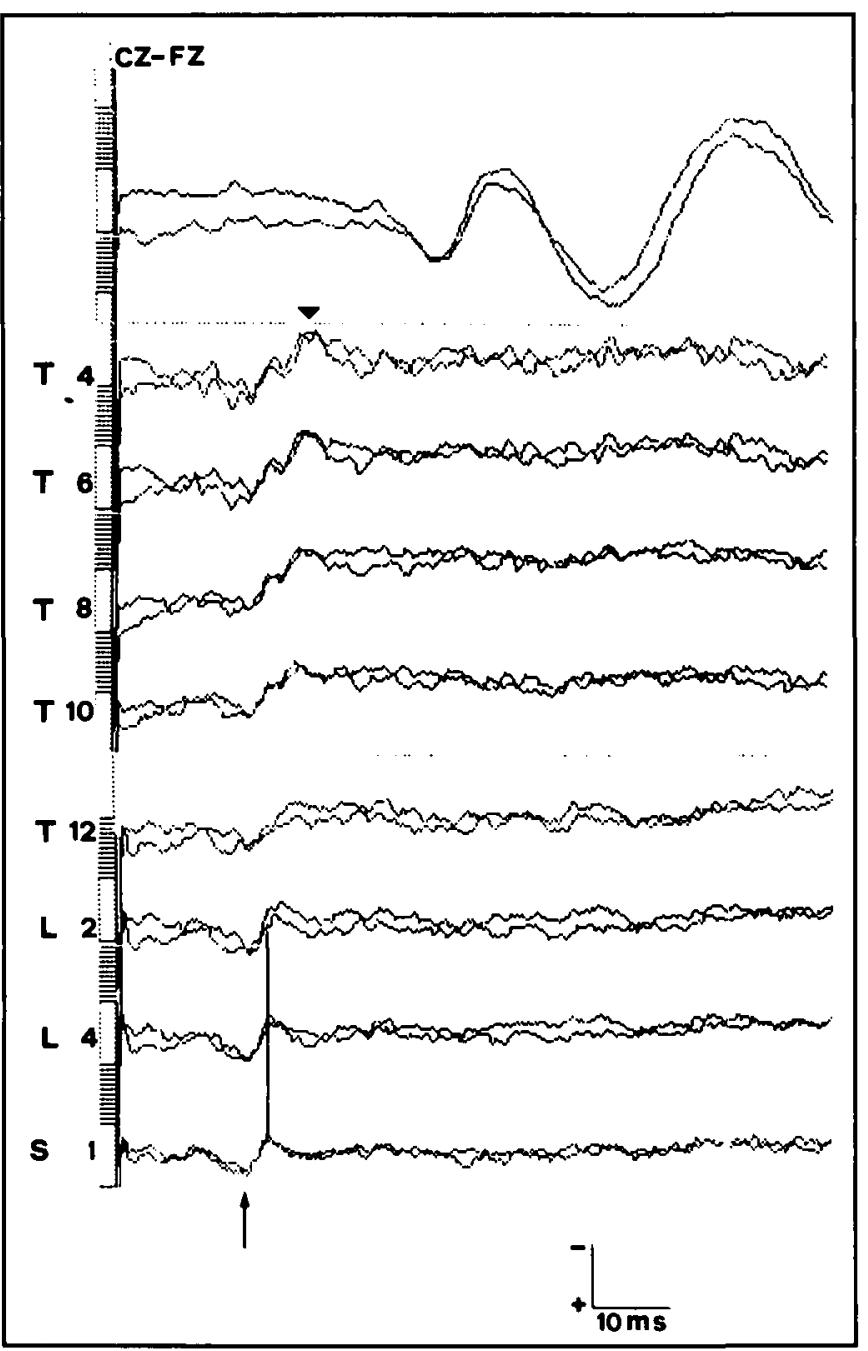

Figure 4: EESG and scalp SEPs in patient 3. In the EESG recording, the positive far field potential $(P I 5)$ is observed at normal latency (arrow at bottom). The negative peaks (NI8 and N22) of the spinal complex are not identifiable. A negative peak, following the P15, may be found at the sacral site $S I$ and at the lower lumbar site L4 with identical latency (vertical line). At the lower dorsal sites (T/2-T10) only the stationary positive peak (PIS) can be observed. At more rostral sites, a synchronized potential (arrow at top) may be identified. The latency (37.8 msec) and amplitude of the scalp responses are normal. Calibration: $0.65 \mu \mathrm{V} / d i v$ in the EESG, $1.3 \mu \mathrm{V} / \mathrm{div}$ in scalp SEPs.

segments that receive the afferent fibres from the posterior tibial nerve.

The abnormal field distribution of the EESG over the lumbosacral spine observed in 2 patients may therefore reflect the rostrocaudal displacement of the spinal cord segments generating the N22. In the other patients, with clinical evidence of segmental dysfunction of the lower cord, the absence of an N22 wave suggests a coexisting gray matter lesion.

At least as regards the analogus responses after upper limb stimulation, this pattern has been demonstrated in selective lesions of the cervical gray matter. ${ }^{26-28}$

The mechanism of lesions to the spinal cord during stretching is very complex and incompletely understood; various types of experimental spinal cord injuries have been studied using electrophysiological techniques in an attempt to clarify the pathophysiology of nerve damage.

The progressive distraction of the spinal cord involves the stationary post-synaptic wave first, whereas the earlier plexus and dorsal root component are very resistant to the stretching. These electrophysiological findings are related to the different sensitivities of the white and gray matter to ischaemia observed on monitoring the cord blood flow. ${ }^{29-32}$

Some authors ${ }^{33}$ believe that the mechanical effect of tethering results in stretching, distortion and kinking of small blood vessels, which may produce anoxia or ischaemia of the spinal cord with impairment of the mitochondrial oxidative metabolism. Hypoxic stress of the lumbosacral spinal cord in the tethering model causes deterioration of a considerable proportion of the neurons, especially the interneurons, before causing long-tract damage.

These experimental data provide strong support for the clinical interpretation of electrophysiological findings. The dorsal horn potential N22 is a response to inputs from axon collaterals and appears to be distinct from the travelling wave in the dorsal columns propagating to the brain. The selective loss of the dorsal horn potential may occur with a complete sparing of the central afferent conduction in TCS. However, in early-onset TCS with malformations there is electrophysiological evidence of involvement of the central pathways: this is probably related to both the extent and the severity of the clinical picture. ${ }^{23}$

The clinical course in less severe, slowly progressive forms is characterized by symptoms such as low back pain, sphincter disturbance and leg weakness mainly due to lower motor neuron dysfunction. Extensive major gray matter damage is also suggested by the selective involvement of the N22 spinal component in these cases. The occurrence of long-tract signs, such as muscle weakness with hyperreflexia or the Babinski sign, could appear later with worsening of the disease. ${ }^{9.10 .34}$ The absence or the existence of spinal pathway involvement thus reflects the extent and severity of the cord damage and parallel electrophysiological monitoring may be useful, alongside the clinical examination, to identify the nervous dysfunction as early as possible.

\section{REFERENCES}

1. Lassman, LP and James CCM. Lumbosacral lipomas: critical survey of 26 cases submitted to laminectomy. J Neurol Neurosurg Psychiatry 1967; 30: 174-181.

2. Dale AJD. Diastematomyelia. Arch Neurol 1969; 20: 309-317.

3. Bruce DA and Schut L. Spinal lipoma in infancy and childhood. Child's Brain 1979; 5: 192-203.

4. Chehrazy B and Haldeman S. Adult onset of tethered spinal cord syndrome due to fibrous diastematomyelia: case report. Neurosurgery 1985; 6: 681-685.

5. Holtzmann RNN, Stein BM, eds.: The Tethered Spinal Cord. New York: Thieme-Stratton, 1985.

6. Barolat, G Schaefer D and Zeme S. Recurrent spinal cord tethering by sacral nerve root following lipomyelomeningocele surgery. $\mathbf{J}$ Neurosurg 1991; 74: 143-145.

7. Fitz CR. Congenital anomalies of the spine and spinal cord. Computed tomography of head, neck and spine. In: Ratchaw RE, ed. Chicago, Year Book, 1985: 715-736.

8. Merx JL, Bakker-Niezen SH, Thijssen HOM and Walder HAD. The tethered spinal cord syndrome: a correlation of radiological features and preoperative findings in 30 patients. Neuroradiology 1989; 31: 63-70.

9. Hendrick EB, Hoffman HJ and Humphreys RP. The tethered spinal cord. Clin Neurosurg 1983; 30: 457-463.

10. Pang $D$ and Wildberger $J E$. Tethered cord syndrome in adults. $J$ Neurosurg 1982; 57: 32-47. 
11. Hoffman HJ, Hendrick EB and Humphreys RP. The tethered spinal cord: its protean manifestations, diagnosis and surgical correction. Child's Brain 1976; 2: 145-155.

12. Welch $\mathrm{K}$ and Winston KR. Spina bifida. In: Myrianthopoulos, NC, ed. Malformations Handbook of Clinical Neurology, Vol 6 (50). Chapter 29. Elsevier Science Publishers BV, 1987: 477-508.

13. Gasser HS and Graham HT. Potentials produced in the spinal cord by stimulation of the dorsal roots. Am J Physiol 1933; 103: 303320.

14. Beall JE, Applebaum AE, Foreman RD and Willis WD. Spinal cord potentials evoked by cutaneous afferents in the monkey. $J$ Neurophysiol 1977; 40: 199-211.

15. Maruyama Y, Shimoji K, Shimizu H, Kuribayashi H and Fujioka $H$. Human spinal cord potentials evoked by different sources of stimulation and conduction velocities along the cord. J Neurophysiol 1982; 48: 1098-1107.

16. Delbecke J, McComas AJ and Kopec SJ. Analysis of evoked lumbosacral potentials in man. $J$ Neurol Neurosurg Psychiatry 1978; 41: 293-302.

17. Desmedt JE and Cheron G. Spinal and far field components of the human somatosensory evoked potentials to posterior tibial nerve stimulation analysis with oesophageal derivations and noncephalic reference recording. Electroencephalogr Clin Neurophysiol 1983; 56: 351-361.

18. Cracco RQ and Cracco JB. Somatosensory evoked potentials in man: far field potentials. Electroencephalogr. Clin Neurophysiol 1976; $41: 460-466$

19. Kimura J, Mitsudome A, Yamada T and Dickins QS. Stationary peaks from a moving source in far field recording. Electroencephalogr Clin Neurophysiol 1984, 58: 351-361.

20. Seyal $M$ and Gabor AJ. The human posterior tibial somatosensory evoked potential:dependent and independent spinal components. Electroencephalogr Clin Neurophysiol 1985; 62: 323-331.

21. Yiannikas $C$ and Shahani BT. The origin of lumbosacral spinal evoked potentials in humans using a surface electrode recording technique. J Neurol Neurosurg Psychiatry 1988; 51: 499-508.
22. Jeanmonod D, Sindou M and Mauguiere F. The human cervical and lumbo-sacral evoked electrospinogram. Data from intra-operative spinal cord surface recordings. Electroencephalogr Clin Neurophysiol 1991; 80: 477-489.

23. Roy MW, Gilmore R and Walsh JW. Evaluation of children and young adults with tethered spinal cord syndrome. Surg Neurol 1986; 26: 241-248.

24. Emerson RG, Pavlakis SG, Carmel PC and De Vivo DC. Spinal somatosensory evoked potentials in the diagnosis of tethered cord. Ann Neurol 1986; 20: 443.

25. Shinomiya K, Fuchioka M, Matsuoka T, et al. Intraoperative monitoring for tethered spinal cord syndrome. Spine 1991; 16:12901294.

26. Emerson RG, Pedley TA. Effect of cervical spinal cord lesions on early components of the median nerve somatosensory evoked potential. Neurology 1986; 36: 20-26.

27. Urasaki E, Wada S, Kadoya C, et al. Absence of spinal NI3-P13 and normal scalp far-field Pl4 in a patient with syringomyelia. Electroencephalogr Clin Neurophysiol 1988; 71: 400-404.

28. Ibanez V, Fischer G, Mauguiere F. Dorsal horn and dorsal column dysfunction in intramedullary cervical cord tumor. Brain 1992; 115: 1209-1234.

29. Schramm J, Hashizume K, Fukushima $T$ and Takahashi $H$. Experimental spinal cord injury produced by slow, graded compression (alterations of cortical and spinal evoked potentials). J Neurosurg 1979; 50: 48-57.

30. Dolan EJ, Transfeldt EE, Tator CH, Simmons EH and Hughes KF. The effect of spinal distraction on regional spinal cord blood flow in cats. J Neurosurg 1980; 53: 756-764.

31. Cusik JF, Myklebust J, Zyvolosky M, et al. Effects of vertebral column distraction in the monkey. J Neurosurg 1982; 57: 651-659.

32. Fujita $Y$ and Yamamoto $H$. An experimental study on spinal cord traction effect. Spine 1989; 14: 698-705.

33. Yamada S, Zinke DE and Sanders D. Pathophysiology of "tethered cord syndrome". J Neurosurg 1981; 54: 494-503.

34. Yashon D and Beatty RA. Tethering of the conus medullaris within the sacrum. J Neurol Neurosurg Psychiatry 1966; 29: 244-250. 